\title{
Lack of pharmacokinetic drug-drug interaction between ramucirumab and paclitaxel in a phase II study of patients with advanced malignant solid tumors
}

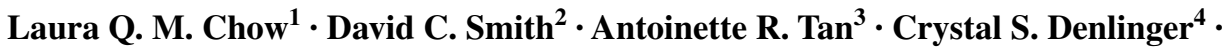 \\ Ding Wang ${ }^{5}$ Dale R. Shepard ${ }^{6} \cdot$ Archana Chaudhary $^{7} \cdot$ Yong Lin $^{7} \cdot$ Ling Gao $^{8}$
}

Received: 26 May 2016 / Accepted: 22 June 2016 / Published online: 5 July 2016

(C) The Author(s) 2016. This article is published with open access at Springerlink.com

\begin{abstract}
Purpose The objective of this phase II study was to evaluate pharmacokinetic interaction potential between ramucirumab and paclitaxel in patients with advanced cancer. Methods This study was designed to assess 2-way pharmacokinetic drug-drug interactions between ramucirumab and paclitaxel. Twenty-four patients participated in Part A, which consisted of a 2-week monotherapy period in which paclitaxel $80 \mathrm{mg} / \mathrm{m}^{2}$ was administered on day 1 , followed by a 4 -week cycle of combination treatment with ramucirumab $(8 \mathrm{mg} / \mathrm{kg}$ on days 1 and 15 ; paclitaxel on days 1 , 8 , and 15). Patients could continue to receive combination therapy with ramucirumab and paclitaxel. In 16 patients in Part B, ramucirumab monotherapy was administered on day 1 of a 3 -week cycle. Patients could continue to receive ramucirumab monotherapy or combination therapy with paclitaxel.

Results Concomitant administration of ramucirumab had no effect on pharmacokinetics of paclitaxel, with ratios of
\end{abstract}

Laura Q. M. Chow

lchow@seattlecca.org

1 University of Washington, Seattle Cancer Care Alliance, MSG4-940, 825 Eastlake Ave E, Box 358081, Seattle, WA 98109, USA

2 University of Michigan, Ann Arbor, MI, USA

3 Rutgers Cancer Institute of New Jersey, New Brunswick, NJ, USA

4 Fox Chase Cancer Center, Philadelphia, PA, USA

Henry Ford Hospital, Detroit, MI, USA

6 Cleveland Clinic Foundation, Cleveland, OH, USA

7 Eli Lilly and Company, Indianapolis, IN, USA

8 Eli Lilly and Company, Bridgewater, NJ, USA geometric least squares (LS) means (with ramucirumab vs. alone) of 1.09 (90\% confidence interval [CI] 0.93, 1.29) for $\mathrm{AUC}_{(0-\infty)}$ and $0.97(90 \% \mathrm{CI} 0.83,1.13)$ for $C_{\max }$. In addition, similar ramucirumab pharmacokinetic characteristics were observed with or without paclitaxel administration. The ratios of geometric LS means of $\mathrm{AUC}_{(0-\infty)}$ and $C_{\max }$ of ramucirumab (with paclitaxel vs. alone) were 1.00 $(90 \% \mathrm{CI} 0.84,1.19)$ for $\mathrm{AUC}_{(0-\infty)}$ and 1.07 (90 \% CI 0.93, 1.24) for $C_{\max }$, respectively.

Conclusions Concomitant paclitaxel administration is unlikely to affect the pharmacokinetics of ramucirumab, and vice versa. The incidence and severity of adverse events were consistent with the known safety profiles of paclitaxel and ramucirumab.

Keywords Ramucirumab - Paclitaxel · Pharmacokinetics · Drug-drug interactions $\cdot$ Cancer

\section{Introduction}

Pathways that mediate angiogenesis are considered important targets in cancer drug development. Vascular endothelial growth factors (VEGFs) have emerged as key regulators of angiogenesis. VEGF receptor 2 (VEGFR-2) is the primary mediator of proangiogenic effects of VEGF-A, and experimental evidence suggests that the VEGF-A/ VEGFR-2 interaction plays an important role in tumor angiogenesis, a process essential for tumor growth and metastasis [1, 2]. Disruption of the interaction between VEGF-A and VEGFR-2 has proven to have therapeutic application in the treatment of cancer.

Ramucirumab is a recombinant human immunoglobulin G1 monoclonal antibody that specifically binds to the VEGFR-2 receptor with high affinity, preventing binding 
of VEGF-A, VEGF-C, and VEGF-D and inhibiting receptor activation [3, 4]. In patients with previously treated advanced gastric or gastroesophageal junction adenocarcinoma, the results from 2 randomized, phase III trials demonstrated that overall survival was significantly increased in patients who received ramucirumab as monotherapy (hazard ratio [HR] 0.78; $95 \%$ confidence interval [CI] 0.60, $0.998 ; P=0.047)$ and in combination with paclitaxel (HR $0.81 ; 95 \%$ CI $0.68,0.96 ; P=0.017)[5,6]$. These trials led to approval of ramucirumab as second-line therapy for advanced gastric cancer.

Paclitaxel is a cytotoxic agent active against various types of malignancies and is used as a single agent or in combination with other agents for advanced gastric cancer [7, 8]. Paclitaxel is a microtubule inhibitor and is metabolized by cytochromes P450 (CYP) CYP3A4 and CYP2C8 $[9,10]$.

An increase in chemotherapy-associated toxicities such as neutropenia has been observed with the addition of anti-VEGF antibodies [11]. In ECOG 4599, a randomized phase III trial in non-squamous non-small cell lung cancer (NSCLC), patients received paclitaxel/carboplatin with or without bevacizumab [12]. In this trial, the rates (grade $\geq 4$ hematologic; grade $\geq 3$ non-hematologic) of hypertension, proteinuria, bleeding, neutropenia, febrile neutropenia, and thrombocytopenia were significantly higher in the paclitaxel/ carboplatin/bevacizumab group than in the paclitaxel/carboplatin group $(P<0.05)$. The underlying mechanism of these events is unknown. An argument could be made whether the pharmacokinetics of chemotherapy can be impacted by coadministration with anti-angiogenic compounds.

To support the concomitant use of ramucirumab with paclitaxel for the treatment of advanced gastric cancer, this phase II study assessed the potential for pharmacokinetic drug-drug interactions (DDIs) between ramucirumab and paclitaxel when given in combination in patients with advanced malignant solid tumors.

\section{Methods}

\section{Patients}

This study was a 2-part, multicenter, open-label phase II study in patients with advanced solid tumors (ClinicalTrials.gov: NCT01515306). Eligible patients were 18 years of age or older; had metastatic or locally advanced malignant solid tumors that were resistant to standard therapy or for which no standard therapy was available; had adequate organ and hematologic function; had no history of uncontrolled hypertension or bleeding; and had an ECOG PS of 0-2. For Part A only, patients were required to have had 1 or fewer prior taxane-containing treatment regimens (including taxane monotherapy), which should have been completed at least 6 months before the first dose of study drug. Prior treatment with bevacizumab was allowed. For Part B only, prior bevacizumab and taxane-containing treatment regimens (including taxane monotherapy) were allowed and should have been completed at least 6 months before the first dose of study drug. The study was undertaken in accordance with principles of the Declaration of Helsinki and Good Clinical Practice guidelines and with local institutional review board approval. Written informed consent was obtained from all participants.

\section{Treatment}

This study was designed to assess 2-way pharmacokinetic DDIs between ramucirumab and paclitaxel.

Part A consisted of a 2-week monotherapy period (Cycle 1), during which paclitaxel $80 \mathrm{mg} / \mathrm{m}^{2}$ was administered on day 1 , followed by a 4-week cycle of combination treatment (Cycle 2). Ramucirumab ( $8 \mathrm{mg} / \mathrm{kg}$ ) was administered on days 1 and 15 , and paclitaxel $\left(80 \mathrm{mg} / \mathrm{m}^{2}\right)$ was administered on days 1,8 , and 15 of each 4-week treatment cycle. This was followed by continuation of the treatment phase (Cycle 3 and beyond), in which patients could continue to receive combination therapy with ramucirumab and paclitaxel.

In Part $\mathrm{B}$, ramucirumab $8 \mathrm{mg} / \mathrm{kg}$ monotherapy was administered on day 1 of a 3 -week cycle. This was followed by continuation of the treatment phase (Cycle 2 and beyond), in which patients could continue to receive ramucirumab $8 \mathrm{mg} / \mathrm{kg}$ monotherapy or combination therapy with paclitaxel.

All patients who completed Cycle 1, Day 1 and Cycle 2, Day 1 in Part A and Cycle 1, Day 1 in Part B were included in the DDI analysis.

\section{Pharmacokinetics}

In Part A, on Day 1 of Cycle 1, blood samples for paclitaxel concentration analysis were drawn at time point 0 (immediately before initiation of paclitaxel infusion) and at $1,1.5$, $2,5,7,24,48,72$, and $168 \mathrm{~h}$ after the start of the paclitaxel infusion. For Cycle 2, blood samples for paclitaxel and ramucirumab concentration analysis were drawn at day 1 , time point 0 (immediately before initiation of ramucirumab infusion) and at 1, 1.5, 2, 5, 7, 24, 48, 72, 96, 168, 264, and $336 \mathrm{~h}$ after the start of the ramucirumab infusion.

In Part B, on Day 1 of Cycle 1, blood samples for ramucirumab concentration analysis were drawn at time point 0 (immediately before initiation of ramucirumab infusion) and at 1, 1.5, 2, 5, 7, 24, 48, 72, 168, 264, 336, 408, and $504 \mathrm{~h}$ after the start of the ramucirumab infusion.

Plasma samples were analyzed for paclitaxel using a validated liquid chromatography tandem mass spectrometry 
method (PPD method LCMSC 163.4 version 1.00) at PPD (Richmond, VA, USA). Serum samples were analyzed for ramucirumab using a modified validated enzyme-linked immunosorbent assay (ELISA) method at Intertek Pharmaceutical Services (San Diego, California, USA).

Pharmacokinetic parameters were assessed for ramucirumab and paclitaxel and were calculated by standard non-compartmental methods of analysis using Phoenix ${ }^{\circledR}$ WinNonlin ${ }^{\circledR}$ Professional 6.2. Area under the curve versus time curve from $t=0$ extrapolated to infinity $\left(\mathrm{AUC}_{(0-\infty)}\right)$ and $C_{\max }$ was dose normalized for the DDI comparisons because patients received different absolute doses.

\section{Statistical analyses}

Log-transformed pharmacokinetic parameters of $\mathrm{AUC}_{(0-\infty)}$ and $C_{\max }$ for paclitaxel were analyzed via a linear mixedeffects model containing treatment (paclitaxel; ramucirumab plus paclitaxel) as a fixed effect and patient as a random effect in Part A.

LS means and $90 \%$ CIs for the differences between $\mathrm{AUC}_{(0-\infty)}$ and $C_{\max }$ of paclitaxel in log scale between Cycle 1 and 2 were estimated before transformation back to the original scale to estimate the ratio of geometric means and $90 \%$ CIs for the comparisons (ramucirumab plus paclitaxel vs. paclitaxel).

A 2-sample $t$ test was used to analyze the log-transformed pharmacokinetic parameters of $\mathrm{AUC}_{(0-\infty)}$ and $C_{\max }$ for ramucirumab when coadministered with paclitaxel (Part A) and for ramucirumab monotherapy (Part B).

All calculations were performed using $\mathrm{SAS}^{\circledR}$ version 9.2.

\section{Safety}

All patients receiving at least one dose of a study drug were included in the summary and analysis of safety in Parts A and B of the study. All enrolled patients were assessed for toxicity before each infusion using National Cancer Institute Common Terminology Criteria for Adverse Events (NCI-CTCAE) v. 4.0.

\section{Results}

\section{Patient demographics and disease characteristics}

\section{Part A}

Twenty-four patients (11 males [45.8\%] and 13 females [54.2\%]) between the ages of 23 and 83 years (median age 60.5 years) participated in Part A of this study (Table 1). The majority of patients had an Eastern Cooperative Oncology Group (ECOG) performance status (PS) of 0 or 1 (20
Table 1 Patient demographics and disease characteristics

\begin{tabular}{|c|c|c|}
\hline Characteristic & $\begin{array}{l}\text { Part A } \\
(n=24)\end{array}$ & $\begin{array}{l}\text { Part B } \\
(n=16)\end{array}$ \\
\hline \multicolumn{3}{|l|}{ Gender, $n(\%)$} \\
\hline Male & $11(46)$ & $7(44)$ \\
\hline Female & $13(54)$ & $9(56)$ \\
\hline \multicolumn{3}{|l|}{ Age, years } \\
\hline Median, (range) & $60.5(23-83)$ & $61.0(19-83)$ \\
\hline$<65, n(\%)$ & $14(58)$ & $10(63)$ \\
\hline$\geq 65, n(\%)$ & $10(42)$ & $6(38)$ \\
\hline \multicolumn{3}{|l|}{ Race, $n(\%)$} \\
\hline Asian & $1(4)$ & $1(6)$ \\
\hline White & $22(92)$ & $15(94)$ \\
\hline Multiple & $1(4)$ & 0 \\
\hline \multicolumn{3}{|l|}{ Ethnicity, $n(\%)$} \\
\hline Hispanic or Latino & $1(4)$ & 0 \\
\hline Non-Hispanic or Latino & $23(96)$ & $16(100)$ \\
\hline \multicolumn{3}{|l|}{ ECOG PS, $n(\%)$} \\
\hline 0 & $6(25)$ & $9(56)$ \\
\hline 1 & $14(58)$ & $6(38)$ \\
\hline 2 & $4(17)$ & $1(6)$ \\
\hline \multicolumn{3}{|l|}{ Duration of disease, months } \\
\hline Median (range) & $35(3-174)$ & $17(2-64)$ \\
\hline $\begin{array}{l}\text { Prior (21 days) anticancer treatment, } \\
n(\%)\end{array}$ & $1(4)$ & 0 \\
\hline Prior (14 days) radiotherapy, $n(\%)$ & $3(13)$ & 0 \\
\hline Prior taxane therapy, $n(\%)$ & $2(8)$ & 0 \\
\hline \multicolumn{3}{|l|}{ Type of cancer, ${ }^{a} n(\%)$} \\
\hline Breast & $4(17)$ & 0 \\
\hline Non-small cell lung & $3(13)$ & $2(13)$ \\
\hline Sarcoma, soft tissue & $3(13)$ & $4(25)$ \\
\hline Urothelial & $3(13)$ & 0 \\
\hline Hepatobiliary & 0 & $2(13)$ \\
\hline
\end{tabular}

ECOG PS Eastern Cooperative Oncology Group performance status

a Part A, one patient each (4.2\%): colorectal, gastric, melanoma, mesothelioma, neuroendocrine tumor, ovarian, cholangiocarcinoma, chondrosarcoma, leiomyosarcoma, squamous cell carcinoma of the tonsil, unknown primary site. Part B, one patient each (6.3\%): mesothelioma, neuroendocrine tumor, pancreatic, small cell lung, urothelial, extrapulmonary small cell, large cell neuroendocrine tumor of the lung, mucinous biliary cyst adenocarcinoma

patients, $83.3 \%)$. Four patients (16.7 \%) had an ECOG PS of 2. Breast carcinoma (4 patients, $16.7 \%$ ) followed by NSCLC, soft tissue sarcoma, and urothelial carcinoma (3 patients each, $12.5 \%$ ) were the most commonly reported sites of origin for the primary tumor.

\section{Part B}

Part B comprised 16 patients (7 males [43.8\%] and 9 females [56.3\%]) between the ages of 19 and 83 years 
(median age 61.0 years). The majority of patients in Part B had an ECOG PS of 0 or 1 (15 patients, $93.8 \%$ ). Only one patient $(6.3 \%)$ had an ECOG PS of 2. Soft tissue sarcoma (4 patients, $25.0 \%$ ) followed by hepatobiliary carcinoma and NSCLC ( 2 patients each, $12.5 \%$ ) were the most commonly reported sites of origin for the primary tumor.

\section{Pharmacokinetic analysis}

Concentrations of paclitaxel and ramucirumab were determined in 23 patients in Part A and 16 patients in Part B. No pharmacokinetic parameters were calculated for one patient in Part A because of an infusion duration of approximately $4 \mathrm{~h}$.

\section{Paclitaxel pharmacokinetics}

Figure 1a shows mean plasma concentrations of paclitaxel over time after monotherapy (Part A, Cycle 1) and combination therapy (Part A, Cycle 2). Overlapped paclitaxel pharmacokinetic profiles were observed between monotherapy and combination therapy. Maximum paclitaxel plasma concentrations were achieved at the end of paclitaxel infusion and then declined in a biexponential fashion, consistent with previously reported profiles [13, 14]. Statistical analysis demonstrated that coadministration of ramucirumab had no effect on dose-normalized area under the curve $\left(\mathrm{AUC}_{(0-\infty)}\right)$ and maximum drug concentration $\left(C_{\max }\right)$
Fig. 1 Mean $( \pm S D)$ plasma concentration-time profile of paclitaxel from Part A, Cycle 1 (monotherapy) and Cycle 2 (combination therapy); inset: concentration curve from 0 to $9 \mathrm{~h}(\mathbf{a})$. Mean $( \pm \mathrm{SD})$ serum concentration-time profile of ramucirumab from Part A, cycle 2 (combination therapy), and Part B, cycle 1 (monotherapy); inset: concentration curve from 0 to $25 \mathrm{~h}(\mathbf{b})$. $H$ hour, $S D$ standard deviation
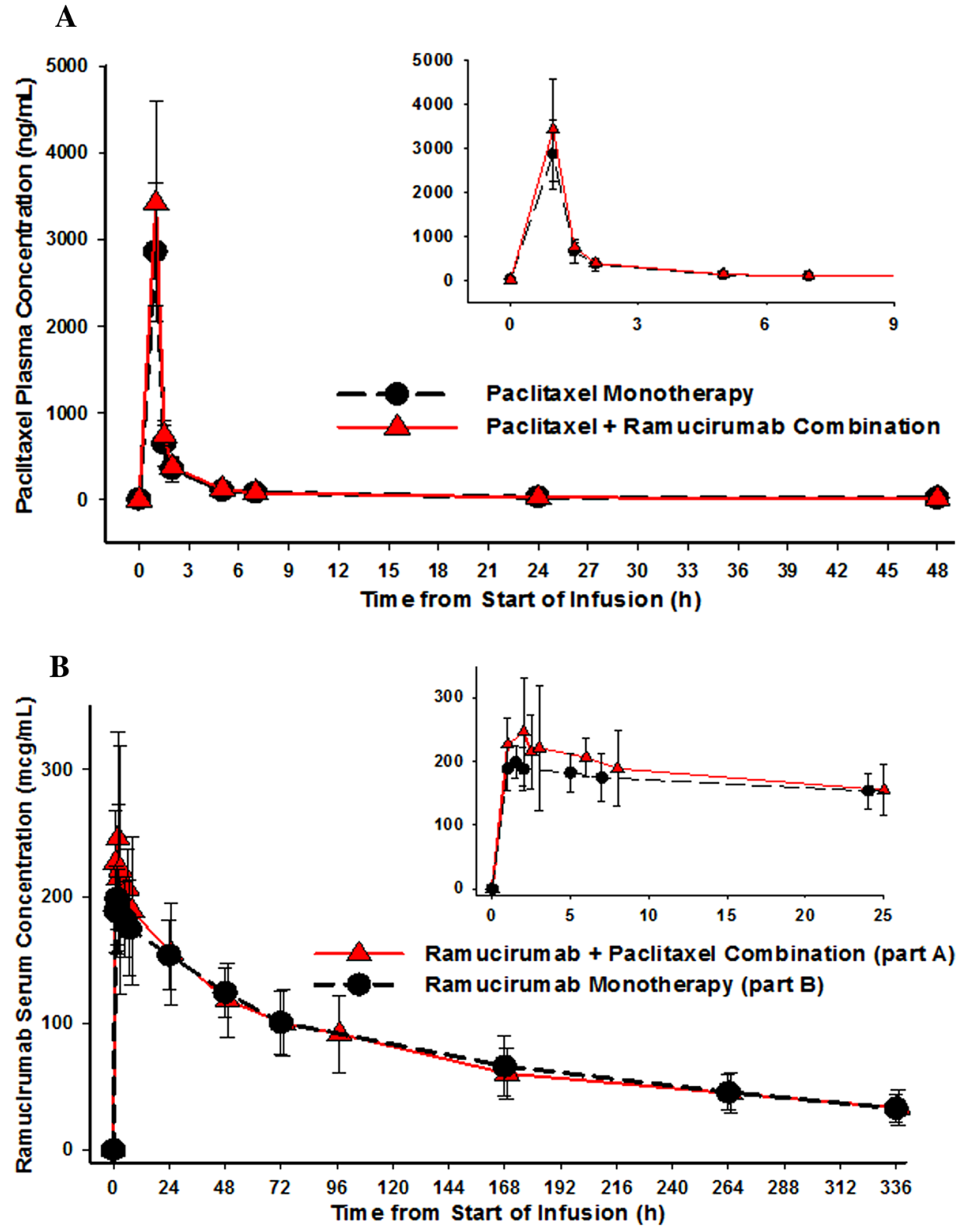
Table 2 Drug-drug interaction assessment

\begin{tabular}{|c|c|c|c|c|c|}
\hline Analyses and $\mathrm{PK}$ parameters ${ }^{\mathrm{a}}$ & $n$ & $\begin{array}{l}\text { Geometric LSM } \\
(90 \% \mathrm{CI})\end{array}$ & $n$ & $\begin{array}{l}\text { Geometric LSM } \\
(90 \% \mathrm{CI})\end{array}$ & $\begin{array}{l}\text { Ratio of geometric LSM } \\
(90 \% \mathrm{CI})\end{array}$ \\
\hline $\begin{array}{l}\text { The effect of coadministration of } \\
\text { ramucirumab on paclitaxel }\end{array}$ & & Paclitaxel alone cycle 1 Part A & & $\begin{array}{l}\text { Ramucirumab+ paclitaxel } \\
\text { cycle } 2 \text { Part A }\end{array}$ & $\begin{array}{l}\text { Ramucirumab+ paclitaxel: } \\
\text { paclitaxel }\end{array}$ \\
\hline $\operatorname{AUC}_{(0-\infty)}(\mathrm{ng} \mathrm{h} / \mathrm{mL} / \mathrm{mg})$ & 19 & $29.00(24.50,34.34)$ & 17 & $31.67(26.58,37.73)$ & $1.09(0.93,1.29)$ \\
\hline$C_{\max }(\mathrm{ng} / \mathrm{mL} / \mathrm{mg})$ & 21 & $18.84(16.03,22.13)$ & 20 & $18.30(15.54,21.56)$ & $0.97(0.83,1.13)$ \\
\hline $\begin{array}{l}\text { The effect of coadministration of } \\
\text { paclitaxel on ramucirumab }\end{array}$ & & $\begin{array}{l}\text { Ramucirumab alone cycle } 1 \\
\text { Part B }\end{array}$ & & $\begin{array}{l}\text { Ramucirumab+ paclitaxel } \\
\text { cycle } 2 \text { Part A }\end{array}$ & $\begin{array}{l}\text { Ramucirumab }+ \text { paclitaxel: } \\
\text { ramucirumab }\end{array}$ \\
\hline $\mathrm{AUC}_{(0-\infty)}(\mathrm{ng} \mathrm{h} / \mathrm{mL} / \mathrm{mg})$ & 15 & $55.32(48.97,62.50)$ & 13 & $55.43(48.63,63.18)$ & $1.00(0.84,1.19)$ \\
\hline$C_{\max }(\mathrm{ng} / \mathrm{mL} / \mathrm{mg})$ & 16 & $0.36(0.33,0.39)$ & 21 & $0.38(0.34,0.43)$ & $1.07(0.93,1.24)$ \\
\hline
\end{tabular}

$A U C_{(0-\infty)}$ area under the plasma concentration versus time curve from time zero extrapolated to infinity, $C I$ confidence interval, $C_{m a x}$ maximum plasma drug concentration, $L S M$ least squares mean, $n$ number of patients included in the analysis, $P K$ pharmacokinetics

${ }^{a}$ For the population of patients who completed Cycle 1, Day 1 and Cycle 2, Day 1

Table 3 Paclitaxel pharmacokinetic parameters as monotherapy or as combination therapy

\begin{tabular}{lll}
\hline Parameter & Geometric mean (CV\%) & \multicolumn{1}{c}{$\begin{array}{l}\text { Paclitaxel + ramucirumab (cycle 2) } \\
\left(n=20^{\mathrm{a}}\right)\end{array}$} \\
\cline { 2 - 3 }$C_{\max }(\mathrm{ng} / \mathrm{mL})$ & $\begin{array}{l}\text { Paclitaxel alone (cycle 1) } \\
(n=23)\end{array}$ & $2662.40(47)$ \\
Dose-normalized $C_{\max }(\mathrm{ng} / \mathrm{mL} / \mathrm{mg})$ & $2742.61(30)$ & $18.5(54)$ \\
$t_{1 / 2}^{\mathrm{b}}(\mathrm{h})$ & $19.1(33)$ & $11.4^{\mathrm{d}}(6.97-15.6)$ \\
$\mathrm{AUC}$ & $11.4^{\mathrm{c}}(8.26-18.9)$ & $4560^{\mathrm{d}}(46)$ \\
Dose-normalized AUC & $(\mathrm{ng} \mathrm{h} / \mathrm{mL})$ & $31.4^{\mathrm{d}}(52)$ \\
$\mathrm{CL}(\mathrm{L} / \mathrm{h})$ & $4280^{\mathrm{c}}(29)$ & $31.9^{\mathrm{d}}(52)$ \\
$V_{\mathrm{ss}}(\mathrm{L})$ & $29.7^{\mathrm{c}}(36)$ & $226^{\mathrm{d}}(72)$ \\
\hline
\end{tabular}

$A U C_{(0-\infty)}$ area under the plasma concentration versus time curve from time zero extrapolated to infinity, $C_{\max }$ maximum plasma drug concentration, $C L$ clearance, $C V \%$ percentage coefficient of variation, $n$ number of subjects who had data for calculation of at least one pharmacokinetic parameter, $t_{1 / 2}$ terminal half-life, $V_{s s}$ volume of distribution at steady state following intravenous administration

a 21 subjects completed Cycle 2, Day 1, but no pharmacokinetic parameters were calculated for one patient because of an infusion duration of $4.32 \mathrm{~h}$

${ }^{\mathrm{b}}$ Geometric mean (range)

${ }^{\mathrm{c}} n=21$

d $n=17$

of paclitaxel; ratios (Part A, Cycle 2 vs. Cycle 1) of geometric least squares (LS) means were 1.09 (90 \% CI 0.93, 1.29 ) and 0.97 (90\% CI 0.83, 1.13), respectively (Table 2). Other pharmacokinetic parameters were also similar between paclitaxel monotherapy and in combination with ramucirumab (Table 3).

\section{Ramucirumab pharmacokinetics}

As shown in Fig. 1b, mean serum concentrations of ramucirumab over time in combination with paclitaxel (Part A, Cycle 2) and as monotherapy (Part B, Cycle 1) were similar. Ramucirumab pharmacokinetic parameters between monotherapy and in combination with paclitaxel were also comparable (Table 4). Statistical analysis was performed to assess the effect of coadministration of paclitaxel on the pharmacokinetics of ramucirumab. Dose-normalized $\mathrm{AUC}_{(0-\infty)}$ and $C_{\max }$ of ramucirumab in Cycle 2 of Part A were similar to those when ramucirumab was administered alone in Cycle 1 of Part B, with ratios (Part A, Cycle 2 vs. Part B, Cycle 1) of geometric means of 1.00 (90 \% CI 0.84, 1.19) for $\mathrm{AUC}_{(0-\infty)}$ and $1.07(90 \% \mathrm{CI} 0.93,1.24)$ for $C_{\max }$ (Table 2).

\section{Safety}

\section{Part A}

In Part A, paclitaxel was administered in Cycle $1(n=24)$, and ramucirumab plus paclitaxel was administered in 
Table 4 Ramucirumab pharmacokinetic parameters as combination therapy or as monotherapy

\begin{tabular}{lll}
\hline Parameter & Geometric mean $(\mathrm{CV} \%)$ & Part B \\
\cline { 2 - 3 } & Part A & $\begin{array}{l}\text { Ramucirumab alone (cycle 1) } \\
(n=16)\end{array}$ \\
\hline$C_{\max }(\mu \mathrm{g} / \mathrm{mL})$ & $\begin{array}{l}\text { Paclitaxel }+ \text { ramucirumab (cycle 2) } \\
(n=21)\end{array}$ & $205.71(14)$ \\
Dose-normalized $C_{\max }(\mu \mathrm{g} / \mathrm{mL} / \mathrm{mg})$ & $216.41(24)$ & $0.358(18)$ \\
$t_{1 / 2}^{\mathrm{a}}(\mathrm{h})$ & $0.384(31)$ & $157^{\mathrm{c}}(77.9-241)$ \\
$\mathrm{AUC}$ & $139^{\mathrm{b}}(78.5-193)$ & $32100^{\mathrm{c}}(29)$ \\
Dose-normalized AUC & \\
$\mathrm{CL}(\mathrm{L} / \mathrm{h})$ & $29100^{\mathrm{b}}(28)$ & $55.3^{\mathrm{c}}(27)$ \\
$V_{\mathrm{ss}}(\mathrm{L})$ & $55.4^{\mathrm{b}}(27)$ & $0.018^{\mathrm{c}}(27)$ \\
\hline
\end{tabular}

$A U C_{(0-\infty)}$ area under the plasma concentration versus time curve from time zero extrapolated to infinity, $C_{\max }$ maximum plasma drug concentration, $C L$ clearance, $C V \%$ percentage coefficient of variation, $n$ number of subjects who had data for calculation of at least one pharmacokinetic parameter, $t_{1 / 2}$ terminal half-life, $V_{s s}$ volume of distribution at steady state following intravenous administration

${ }^{a}$ Geometric mean (range)

b $n=13$

${ }^{c} n=15$

Cycle $2+(n=21)$. In Cycle 1, 2 patients $(8.3 \%)$ discontinued due to a treatment-emergent adverse event (TEAE): 1 patient discontinued due to grade 3 increased hepatic enzymes, and 1 patient discontinued due to a grade 2 infusion-related reaction. Two patients $(8.3 \%)$ had a reduced or interrupted dose in Cycle 1 due to neutropenia and infusion-related reaction. In Cycle 2 or beyond, 1 $(4.8 \%)$ patient discontinued study treatment due to grade 3 anemia. In the safety population in Part A, 10 patients (41.7\%) had a TEAE leading to dose reduction or interruption, $7(29.2 \%)$ of which were grade 3 . Reasons for dose modifications included grade 3 neutropenia, paresthesia, hypophosphatemia, influenza and grade 2 neutropenia and infusion-related reaction. TEAEs occurring in at least $10 \%$ of patients are summarized in Table 5. Overall, the most frequent any grade TEAEs were fatigue (12 patients, $50.0 \%$ ), anemia (10 patients, $41.7 \%$ ), and diarrhea, decreased appetite, and epistaxis (7 patients each, $29.2 \%)$.

In Part A, adverse events of special interest (AESI) for patients who received ramucirumab in Cycle 2 and beyond included 8 patients $(38.1 \%)$ who experienced bleeding/hemorrhagic events, including epistaxis (7 patients, $33.3 \%)$ and hemoptysis in 2 patients $(9.5 \%), 1$ with colorectal cancer, and 1 with ovarian cancer. None of these events were grade 3 or greater. Five patients $(23.8 \%)$ experienced hypertension. Of these, 2 patients $(9.5 \%)$ experienced grade 3 hypertension; 1 of these 2 patients had a prior history of hypertension. One patient $(4.8 \%)$ experienced grade 3 pulmonary embolism.

Five of 24 patients $(20.8 \%)$ experienced serious adverse events (SAEs) during Part A. Of these, 3 patients (12.5\%) experienced SAEs that were considered related to study treatment. Three patients $(12.5 \%)$ died due to progressive disease, and 1 patient (4.2\%) died during Cycle 1 in Part A due to an $\mathrm{AE}$ that was not considered related to study treatment but to underlying disease progression.

\section{Part B}

Sixteen patients in Part B received ramucirumab monotherapy in Cycle 1; patients were allowed to continue to receive ramucirumab alone or in combination with paclitaxel. No patient discontinued from the study due to TEAEs in Cycle 1. One patient experienced an AE, leading to dose reduction or interruption in Cycle $2+$ due to an infusionrelated reaction. The most frequent any grade TEAEs were epistaxis (4 patients, $25.0 \%$ ) and nausea (3 patients, $18.8 \%$; Table 5). Six patients (37.5\%) experienced AESIs in Part B. Four patients (25.0\%) experienced bleeding/ hemorrhagic events (epistaxis). One patient each $(6.3 \%)$ experienced mild proteinuria and increased blood creatinine levels. None of these events were grade 3 or greater. No SAEs or deaths occurred in Part B.

\section{Discussion}

The primary objective of this phase II trial was to evaluate potential pharmacokinetic DDIs between ramucirumab and paclitaxel in patients with advanced malignant solid tumors resistant to standard therapy or for whom standard therapy was no longer available. The results demonstrated that no clinically meaningful changes in paclitaxel or ramucirumab 
Table 5 Treatment-emergent adverse events occurring in at least $10 \%$ of patients

\begin{tabular}{|c|c|c|c|c|}
\hline \multirow[t]{2}{*}{ Preferred term } & \multicolumn{2}{|c|}{ Part A $(n=24)$} & \multicolumn{2}{|c|}{ Part B $(n=16)$} \\
\hline & $\begin{array}{l}\text { Any grade } \\
n(\%)\end{array}$ & $\begin{array}{l}\text { Grade } \geq 3 \\
n(\%)\end{array}$ & $\begin{array}{l}\text { Any grade } \\
n(\%)\end{array}$ & $\begin{array}{l}\text { Grade } \geq 3 \\
n(\%)\end{array}$ \\
\hline Fatigue & $12(50)$ & 0 & $2(13)$ & $1(6)$ \\
\hline Anemia & $10(42)$ & $1(4)$ & 0 & 0 \\
\hline Diarrhea & $7(29)$ & 0 & $2(13)$ & 0 \\
\hline Decreased appetite & $7(29)$ & $1(4)$ & 0 & 0 \\
\hline Epistaxis & $7(29)$ & 0 & $4(25)$ & 0 \\
\hline Alopecia & $6(25)$ & 0 & 0 & 0 \\
\hline Constipation & $6(25)$ & 0 & 0 & 0 \\
\hline Nausea & $6(25)$ & 0 & $3(19)$ & 0 \\
\hline Dizziness & $5(21)$ & 0 & 0 & 0 \\
\hline Dyspnea & $5(21)$ & 0 & 0 & 0 \\
\hline Headache & $5(21)$ & 0 & $2(13)$ & 0 \\
\hline Hypertension & $5(21)$ & $2(8)$ & 0 & 0 \\
\hline Pyrexia & $5(21)$ & 0 & 0 & 0 \\
\hline Abdominal pain & $4(17)$ & 0 & $2(13)$ & 0 \\
\hline Back pain & $4(17)$ & $2(8)$ & 0 & 0 \\
\hline Cough & $4(17)$ & $1(4)$ & 0 & 0 \\
\hline Dysgeusia & $4(17)$ & 0 & 0 & 0 \\
\hline Myalgia & $4(17)$ & 0 & 0 & 0 \\
\hline $\begin{array}{l}\text { Neuropathy periph- } \\
\text { eral }\end{array}$ & $4(17)$ & 0 & 0 & 0 \\
\hline Neutropenia & $4(17)$ & $3(13)$ & 0 & 0 \\
\hline Edema peripheral & $4(17)$ & 0 & 0 & 0 \\
\hline $\begin{array}{l}\text { Upper respiratory } \\
\text { tract infection }\end{array}$ & $4(17)$ & 0 & 0 & 0 \\
\hline Vomiting & $4(17)$ & 0 & 0 & 0 \\
\hline Arthralgia & $3(13)$ & 0 & 0 & 0 \\
\hline Dry skin & $3(13)$ & 0 & 0 & 0 \\
\hline Flushing & $3(13)$ & 0 & 0 & 0 \\
\hline $\begin{array}{l}\text { Infusion-related } \\
\text { reaction }\end{array}$ & $3(13)$ & 0 & 0 & 0 \\
\hline Pruritus & $3(13)$ & 0 & 0 & 0 \\
\hline Stomatitis & $3(13)$ & 0 & $2(13)$ & 0 \\
\hline Vision blurred & $3(13)$ & 0 & 0 & 0 \\
\hline Weight decreased & $3(13)$ & 0 & 0 & 0 \\
\hline Hyperglycemia & 0 & 0 & $2(13)$ & 0 \\
\hline Insomnia & 0 & 0 & $3(19)$ & 0 \\
\hline Decreased appetite & 0 & 0 & $2(13)$ & 0 \\
\hline Dry mouth & 0 & 0 & $2(13)$ & 0 \\
\hline $\begin{array}{l}\text { Musculoskeletal } \\
\text { pain }\end{array}$ & 0 & 0 & $2(13)$ & 0 \\
\hline Stomatitis & 0 & 0 & $2(13)$ & 0 \\
\hline $\begin{array}{l}\text { Urinary tract infec- } \\
\text { tion }\end{array}$ & 0 & 0 & $2(13)$ & 0 \\
\hline
\end{tabular}

exposure were observed when ramucirumab $8 \mathrm{mg} / \mathrm{kg}$ and paclitaxel $80 \mathrm{mg} / \mathrm{m}^{2}$ were coadministered in patients with solid tumors.
As paclitaxel is mainly metabolized by hepatic cytochrome P450 enzymes and monoclonal antibodies are eliminated through $\mathrm{Fc}$ receptor-mediated immunoglobulin clearance mechanisms and specific target-mediated drug disposition pathways, this finding was not unexpected [10, 15]. In DDI studies with other biologics, similar results were shown. A phase II study evaluating pharmacokinetics and safety found that the combination of paclitaxel and trastuzumab was generally well tolerated, with no unexpected toxicities and no pharmacokinetic interactions in women with human epidermal growth factor receptor 2-overexpressing metastatic breast cancer [16]. Likewise, no pharmacokinetic interactions were found with cetuximab in combination with paclitaxel and carboplatin, and the combination was safe and well tolerated in a population of stage IV NSCLC patients [17].

Systemic taxane-based chemotherapy is commonly used for patients with advanced disease. In a pivotal phase III study (RAINBOW), ramucirumab demonstrated significant improvement in overall survival in combination with paclitaxel versus paclitaxel alone in previously treated patients with advanced gastric cancers [6]. The current study was conducted to primarily support the use of ramucirumab in combination with paclitaxel for treatment in this patient population. Other studies have demonstrated that ramucirumab significantly improved overall survival as monotherapy; in combination with docetaxel; or in combination with irinotecan, folinic acid, and 5-fluorouracil (FOLFIRI) as second-line therapy in gastric, NSCLC, and metastatic colorectal cancer, respectively $[5,18,19]$. Two phase II studies evaluating the effect of concomitant ramucirumab on the pharmacokinetics of docetaxel or FOLFIRI in patients with advanced malignant solid tumors demonstrated no DDI between ramucirumab and these agents [20, 21].

The principal hematologic toxicity associated with paclitaxel is neutropenia [9]. In the RAINBOW trial, the incidence of grade 3 or 4 neutropenia was higher in the ramucirumab/paclitaxel group (grade 3, 71 patients [22\%]; grade 4, 62 patients [19\%]) versus the placebo/paclitaxel group (grade 3, 51 patients [16\%]; grade 4, 11 patients [3\%]) [6]. In this study, grade $\geq 3$ neutropenia occurred in 3 patients (12.5\%) in Part A, and no patients in Part B. Results from this current study suggest that a synergistic effect of ramucirumab on paclitaxel-induced neutropenia is unlikely due to pharmacokinetic interactions.

No unexpected TEAEs or SAEs were observed with ramucirumab monotherapy or in combination with paclitaxel. The incidence and severity of TEAEs were consistent with the known safety profiles of paclitaxel and ramucirumab. Thus, these results demonstrate that no starting dose adjustments are needed for ramucirumab when coadministered with paclitaxel $80 \mathrm{mg} / \mathrm{m}^{2}$, and no starting dose 
adjustments are needed for paclitaxel when coadministered with ramucirumab $8 \mathrm{mg} / \mathrm{kg}$, due to concerns for DDIs.

Acknowledgments The authors gratefully acknowledge Dr. Minori Koshiji for her contributions to this study. This work was supported by Eli Lilly and Company. Eli Lilly and Company contracted with inVentiv Health Clinical for writing and editorial support, provided by Stacey E. Shehin PhD, and Noelle Gasco, respectively. This work was presented in part as an abstract at the American Society of Clinical Oncology Annual Meeting, May 30-June 3, 2014, Chicago, IL, and at the American Association of Pharmaceutical Scientists National Biotechnology Conference, San Diego, CA, May 19-21, 2014.

\section{Compliance with ethical standards}

Conflict of interest Laura Q.M. Chow received remuneration from Astellas, Emergent, Merck, Novartis, and Amgen; has a consultant/ advisory role with Amgen, Merck, and Novartis; received research funding from Bristol-Myers Squibb, Genentech/Roche, Merck, Incyte, Pfizer, Medimmune/AstraZeneca, Novartis, Venti Rx, and Eli Lilly and Company. David C. Smith received funding from Eli Lilly and Company. Antoinette R. Tan received funding from Eli Lilly and Company. Crystal S. Denlinger has a consultant/advisory role with Merrimack and Eli Lilly and Company, received funding from Merrimack, OncoMed, Eli Lilly and Company, MedImmune, Genentech, Bayer, Incyte, and Astex. Ding Wang received funding from Eli Lilly and Company, AstraZeneca, EMD Serono, Merck, Novartis, Bayer and AbbVie Inc. Dale R. Shepard has no conflicts to disclose. Archana Chaudhary, Yong Lin, and Ling Gao are employees of and may own stock in Eli Lilly and Company.

Ethical approval All procedures performed in studies involving human participants were in accordance with the ethical standards of the institutional and/or national research committee and with the 1964 Helsinki Declaration and its later amendments or comparable ethical standards. Written informed consent was obtained from all participants.

Open Access This article is distributed under the terms of the Creative Commons Attribution 4.0 International License (http://creativecommons.org/licenses/by/4.0/), which permits unrestricted use, distribution, and reproduction in any medium, provided you give appropriate credit to the original author(s) and the source, provide a link to the Creative Commons license, and indicate if changes were made.

\section{References}

1. Sullivan LA, Brekken RA (2010) The VEGF family in cancer and antibody-based strategies for their inhibition. MAbs $2: 165-175$

2. Tugues S, Koch S, Gualandi L, Li X, Claesson-Welsh L (2011) Vascular endothelial growth factors and receptors: anti-angiogenic therapy in the treatment of cancer. Mol Aspects Med 32:88-111

3. Spratlin JL, Cohen RB, Eadens M, Gore L, Camidge DR, Diab S, Leong S, O'Bryant C, Chow LQ, Serkova NJ, Meropol NJ, Lewis NL, Chiorean EG, Fox F, Youssoufian H, Rowinsky EK, Eckhardt SG (2010) Phase I pharmacologic and biologic study of ramucirumab (IMC-1121B), a fully human immunoglobulin G1 monoclonal antibody targeting the vascular endothelial growth factor receptor-2. J Clin Oncol 28:780-787

4. Chiorean EG, Hurwitz HI, Cohen RB, Schwartz JD, Dalal RP, Fox FE, Gao L, Sweeney CJ (2015) Phase I study of every 2- or 3-week dosing of ramucirumab, a human immunoglobulin G1 monoclonal antibody targeting the vascular endothelial growth factor receptor-2 in patients with advanced solid tumors. Ann Oncol 26:1230-1237

5. Fuchs CS, Tomasek J, Yong CJ, Dumitru F, Passalacqua R, Goswami C, Safran H, dos Santos LV, Aprile G, Ferry DR, Melichar B, Tehfe M, Topuzov E, Zalcberg JR, Chau I, Campbell W, Sivanandan C, Pikiel J, Koshiji M, Hsu Y, Liepa AM, Gao L, Schwartz JD, Tabernero J, Trial Investigators REGARD (2014) Ramucirumab monotherapy for previously treated advanced gastric or gastro-oesophageal junction adenocarcinoma (REGARD): an international, randomised, multicentre, placebo-controlled, phase 3 trial. Lancet 383:31-39

6. Wilke H, Muro K, Van Cutsem E, Oh SC, Bodoky G, Shimada Y, Hironaka S, Sugimoto N, Lipatov O, Kim TY, Cunningham D, Rougier P, Komatsu Y, Ajani J, Emig M, Carlesi R, Ferry D, Chandrawansa K, Schwartz JD, Ohtsu A, RAINBOW Study Group (2014) Ramucirumab plus paclitaxel versus placebo plus paclitaxel in patients with previously treated advanced gastric or gastro-oesophageal junction adenocarcinoma (RAINBOW): a double-blind, randomised phase 3 trial. Lancet Oncol 15:1224-1235

7. Hironaka S, Zenda S, Boku N, Fukutomi A, Yoshino T, Onozawa Y (2006) Weekly paclitaxel as second-line chemotherapy for advanced or recurrent gastric cancer. Gastric Cancer 9:14-18

8. Kim YH, Shin SW, Kim BS, Kim JH, Kim JG, Mok YJ, Kim CS, Rhyu HS, Hyun JH, Kim JS (1999) Paclitaxel, 5-fluorouracil, and cisplatin combination chemotherapy for the treatment of advanced gastric carcinoma. Cancer 85:295-301

9. Foa R, Norton L, Seidman AD (1994) Taxol (paclitaxel): a novel anti-microtubule agent with remarkable anti-neoplastic activity. Int J Clin Lab Res 24:6-14

10. Desai PB, Duan JZ, Zhu YW, Kouzi S (1998) Human liver microsomal metabolism of paclitaxel and drug interactions. Eur J Drug Metab Pharmacokinet 23:417-424

11. Herbst RS (2006) Toxicities of antiangiogenic therapy in nonsmall-cell lung cancer. Clin Lung Cancer 8:S23-S30

12. Sandler A, Gray R, Perry MC, Brahmer J, Schiller JH, Dowlati A, Lilenbaum R, Johnson DH (2006) Paclitaxel-carboplatin alone or with bevacizumab for non-small-cell lung cancer. $\mathrm{N}$ Engl J Med 355:2542-2550

13. Tamura T, Sasaki Y, Nishiwaki Y, Saijo N (1995) Phase I study of paclitaxel by three-hour infusion: hypotension just after infusion is one of the major dose-limiting toxicities. Jpn J Cancer Res 86:1203-1209

14. Gelderblom H, Baker SD, Zhao M, Verweij J, Sparreboom A (2003) Distribution of paclitaxel in plasma and cerebrospinal fluid. Anticancer Drugs 14:365-368

15. Keizer RJ, Huitema AD, Schellens JH, Beijnen JH (2010) Clinical pharmacokinetics of therapeutic monoclonal antibodies. Clin Pharmacokinet 49:493-507

16. Leyland-Jones B, Gelmon K, Ayoub JP, Arnold A, Verma S, Dias R, Ghahramani P (2003) Pharmacokinetics, safety, and efficacy of trastuzumab administered every three weeks in combination with paclitaxel. J Clin Oncol 21:3965-3971

17. Thienelt CD, Bunn PA Jr, Hanna N, Rosenberg A, Needle MN, Long ME, Gustafson DL, Kelly K (2005) Multicenter phase I/II study of cetuximab with paclitaxel and carboplatin in untreated patients with stage IV non-small-cell lung cancer. J Clin Oncol 23:8786-8793

18. Garon EB, Ciuleanu TE, Arrieta O, Prabhash K, Syrigos KN, Goksel T, Park K, Gorbunova V, Kowalyszyn RD, Pikiel J, Czyzewicz G, Orlov SV, Lewanski CR, Thomas M, Bidoli P, Dakhil S, Gans S, Kim JH, Grigorescu A, Karaseva N, Reck M, Cappuzzo F, Alexandris E, Sashegyi A, Yurasov S, Pérol M (2014) Ramucirumab plus docetaxel versus placebo plus 
docetaxel for second-line treatment of stage IV non-small-cell lung cancer after disease progression on platinum-based therapy (REVEL): a multicentre, double-blind, randomised phase 3 trial. Lancet 384:665-673

19. Tabernero J, Yoshino T, Cohn AL, Obermannova R, Bodoky G, Garcia-Carbonero R, Ciuleanu TE, Portnoy DC, Van Cutsem E, Grothey A, Prausová J, Garcia-Alfonso P, Yamazaki K, Clingan PR, Lonardi S, Kim TW, Simms L, Chang SC, Nasroulah F, RAISE Study Investigators (2015) Ramucirumab versus placebo in combination with second-line FOLFIRI in patients with metastatic colorectal carcinoma that progressed during or after firstline therapy with bevacizumab, oxaliplatin, and a fluoropyrimidine (RAISE): a randomised, double-blind, multicentre, phase 3 study. Lancet Oncol 16:499-508
20. Stein MN, Chow LQM, Smith DC, Shepard DR, Wang D, Powderly JD, Gao L, Lin Y, Koshiji M (2014) Phase II study evaluating the effect of concomitant ramucirumab (IMC-1121B; RAM) on the pharmacokinetics (PK) of docetaxel (DOC) in patients (pts) with advanced malignant solid tumors (abstract). J Clin Oncol 32(suppl):e13539

21. Wang D, Braiteh FS, Lee JJ, Denlinger CS, Shepard DR, Chaudhary A, Lin Y, Gao L, Asakiewicz CJ, Nasroulah F, LoRusso P (2015) Phase II study evaluating the effect of concomitant ramucirumab (RAM) on the pharmacokinetics (PK) of irinotecan (IRI) and its metabolite SN-38 when coadministered with folinic acid (FA) and 5-fluorouracil (5-FU) (FOLFIRI) in patients (pts) with advanced malignant solid tumors (abstract). J Clin Oncol 33(suppl 3):691 